insight, I would doubt the wisdom of including compliance in any scale designed to measure insight. I was interested that such a high correlation between insight on the Present State Examination (PSE) scale and compliance was found. My experience of conducting a survey of patients' knowledge of medication on long-stay psychiatric wards suggested that there was little relationship between patients' willingness to comply with medication, and the degree of insight that they displayed as to their need for the medication or their having a psychiatric illness (McPherson et al, 1993).

This study, conducted on a long-stay population with mean age 63 years, showed an overall extremely poor awareness of medication and its actions, but a willingness to take medication, which did not correlate with the individual's own views as to whether they had a psychiatric illness or not.

As has previously been observed (McAvoy et al, 1989), many patients will comply with treatment while not regarding themselves as ill. This appears to be particularly so in hospitalised patients with chronic psychosis and therefore inclusion of compliance in a measure of insight will lead to erroneously elevated scores in these individuals.

While I would agree wholeheartedly with David $e t$ al that educating patients about their illness and treatment is a vital part of psychiatric practice and should never be neglected, I do not believe that compliance is, per se, an indicator of insight; increasing insight may lead to increased compliance, but compliance does not equate with insight.

McAvoy, J. P., Apperson, J. \& APpelbaum, P. S. (1989) Insight in schizophrenia: its relationship to acute psychopathology. Journal of Nervous and Mental Diseases, 177, 43-47.

McPherson, R., Double, D., Harrison, D., et al (1993) Long-term psychiatric patients' understanding of neuroleptic medication. Hospital and Community Psychiatry, 44, 71-73.

Middlewood Hospital

Paul Rowlands Sheffield S6 ITP

Down's syndrome, longevity, and Alzheimer's disease

SIR: In reply to my correspondence (Journal, November 1992, 161, 722), Dr Harrison implies that there may be a differential association between the aetiological origin of Down's syndrome (trisomy, translocation, or mosaic form) and any resulting Alzheimer-type pathology; and "this could be tested by a combination of cytogenetics and subsequent neuropathological analysis" (Journal, February 1993, 162, 276). Review of the literature already sheds light on such a provoking idea.
Many individuals with complete trisomy 21 (and therefore triplication of the APP gene) do not develop Alzheimer-type dementia (Wisniewski et al, 1985). Although the majority of pathological findings have been in proven cases of complete trisomy 21, cases of Alzheimer-type changes have been described in mosaic forms of Down's syndrome (Whalley, 1982; Sylvester, 1986; Rowe et al, 1989), and in individuals with $21 / 22$ translocations (Sylvester, 1986). In such cases, overexpression of the APP gene is unlikely. The role of cytogenetics in the development of dementia in people with Down's syndrome, therefore, remains complex.

The establishment of a national case register of people with translocated and mosaic forms of Down's syndrome is recommended by the author. Subsequent access to a large sample population of the uncommon forms of Down's syndrome would prove invaluable in the future investigation of Alzheimer's disease, both in the general, and Down's syndrome population.

Rowe, I. F., Ridler, M. A. C. \& Gibeerd, F. B. (1989) Presenile dementia associated with mosaic trisomy 21 in a patient with a Down syndrome child. Lancet, ii, 229.

Sylvester, P. E. (1986) The anterior commissure in Down's syndrome. Journal of Mental Deficiency Research, 30, 19-26.

Whalley, L. J. (1982) The dementia of Down's syndrome and its relevance to aetiological studies of Alzheimer's disease. Annals of the New York Academy of Sciences, 396, 39-53.

WISNIEWSKI, K. E., WISNIEWSKI, H. M. \& WEN, G. Y. (1985) Occurrence of neuropathological changes and dementia of Alzheimer's disease in Down's syndrome. Annals of Neurology, 17, 278-282.

Department of Psychiatry

V. P. Prasher

Birmingham University

Queen Elizabeth Psychiatric Hospital

Mindelsohn Way

Edgbaston

Birmingham B15 2QZ

\section{Association of schizophrenia and Duchenne muscular dystrophy}

SIR: We want to report a case of association of schizophrenia and Duchenne muscular dystrophy (DMD). DMD is a lethal, recessive, $\mathrm{X}$-linked disease leading to a progressive muscle degeneration and wasting: $90 \%$ of the patients die before the age of 20 years (Emery, 1987). It is caused by mutations in the dystrophin gene, which codes for a protein localised in skeletal muscle and in the brain, located at Xp21 segment (Hoffman et al, 1988). The association of DMD and schizophrenia is apparently rare since we have found only two previous reports (Dubowitz \& Crome, 1969; DeLisi \& Crow, 1991). 